\title{
A Trama do Desejo: UMa Leitura do Conto “DesenRedo", de Guimarães RosA
}

\author{
MARÍLIA LIBRANDI ROCHA*
}

Resumo: O presente estudo reelabora uma análise feita há alguns anos sobre o conto "Desenredo" de Guimarães Rosa (Tutaméia, 1967). Na ocasião, procedemos a uma leitura estritamente ligada ao campo da teoria literária, que agora desenvolvemos com o acréscimo de algumas reflexões provenientes da psicanálise e que se baseiam especificamente em dois estudos de Freud: Os Chistes e sua relação como Inconsciente (1905) e Escritores criativos e devaneio (1908).

PalaVras-Chave: Guimarães Rosa; Tutaméia; literatura e psicanálise; chiste; Livro de Jó.

(1) J. Guimarães Rosa. "Desenredo", in Tutaméia Terceiras Estórias (1967). 5. ed. Rio de Janeiro: José Olympio, 1979, p. $38-40$.
O conto "Desenredo", como o próprio título indica, é uma espécie de conto ao avesso, em que se narra a trajetória amorosa de um personagem chamado Jó Joaquim. A situação enunciativa é a de um narrador que fala a seus ouvintes e conta a estória desse homem "quieto, respeitado", até o momento

(^) Mestre em Teoria Literária e Literatura Comparada pela USP. 
(2) Sigmund FREUD. Escritores criativos $e$ devaneio. Rio de Janeiro: Imago, 1976, v. IX, p. 149-60.
(3) Paulo RÓNAI. "Os Prefácios de Tutaméia", in ROSA, Tutaméia -Terceiras Estórias, op. cit., p. 195. em que se encontra com ela, a mulher, cujo nome, "Livíria, Rivília ou Irlívia", é Legião. O caso começa "coberto de sete capas" - pois a mulher é casada e a aldeia é a "alheia vigilância" -, até que a mulher é encontrada com um outro, um terceiro, e Jó Joaquim descobre-se "pseudopersonagem" da trama. Mesmo assim, com a morte providencial do marido, ele com ela se casa "para feliz escândalo popular", sofrendo novamente a traição. Obrigado pela moral e os bons costumes da comunidade, J.J. expulsa-a de casa e volta a ser respeitado, e triste. É chegado então o momento do desenredo, da reviravolta operada pelo personagem, pois J.J. inspira-se na loucura sábia de Ulisses, voltando-se contra a lógica aristotélica e o "público pensamento", e começa a redimir a mulher de acordo com "sua idéia inata de felicidade": "Nunca tivera ela amantes!", tudo não passara de "falsas lérias escabrosas". Com muita paciência, "amatemático", ele começa a "operar o passado", descaluniando-a com tal convicção que todos passam a crer na inocência da mulher, incluindo a própria, que se descobre "nua e pura". Vai então, "Vilíria" volta, e com Jó Joaquim permanece, vivendo "o verdadeiro e o melhor de sua útil vida" - e a fábula é posta "em ata", ou seja, escrita como documento oficial.

Em seu texto Escritores criativos e devaneio, Freud intenta, segundo suas próprias palavras, descobrir em nós mesmos e nos semelhantes uma atividade que seja de uma forma ou de outra próxima da criação literária : "E, na verdade", diz ele "essa perspectiva é possível. Afinal, os próprios escritores criativos gostam de diminuir a distância entre a sua classe e o homem comum, assegurando-nos com muita freqüência de que todos, no íntimo, somos poetas, e de que só com o último homem morrerá o último poeta." ${ }^{2}$ Acreditamos ler em "Desenredo" uma mensagem semelhante, entendendo o personagem Jó Joaquim - que "tinha o para não ser célebre" -, como o homem comum que opera uma reviravolta em seu destino quando resolve inventar uma "estória", atuando de forma semelhante a um poeta (no sentido amplo do termo). Acontece que a grande singularidade e complexidade do conto encontra-se no fato de que a estória inventada vira história, a fábula, fato; o fingimento, verdade. É essa mensagem que nos autoriza a lê-lo como um tratado poético, como um conto que desnuda o próprio fazer literário, fornecendo-nos uma noção de "estória", tal como entendida e defèndida pelo autor.

Sabe-se que Guimarães Rosa era esquivo toda vez que indagado sobre sua própria obra ou a respeito de como escrevia ou quais autores lia, respondendo sempre de forma indireta, desconcertante e paradoxal. Entre seus livros, Tutaméia, publicado poucos meses antes de sua morte, é aquele que mais concentra e fornece dados sobre o que o autor entendia por seu ofício. Não por acaso o livro contém quatro prefácios que, como bem notou Paulo Rónai, "compõem ao mesmo tempo uma profissão de fé e uma arte poética em que o escritor ... analisa o seu gênero, o seu instrumento de expressão, a natureza da sua inspiração, a finalidade da sua arte, de toda arte". ${ }^{3}$ Esses prefácios foram compostos ao modo de estórias, podendo ser lidos como tais (fato confirmado no primeiro índice que não distingue entre os diferentes tipos de texto). Da mesma forma, podemos ler o conto "Desenredo" como uma espécie de prefácio - no sentido de que contém também uma arte poética.

Lembramos que, inicialmente, o personagem de nosso conto é envolvido em duas tramas que não lhe convêm em nada: tanto no papel de amante como no de marido, ele é ludibriado e traído. Nessas duas situações ele sofre a ação 
(4) FREUD. Escritores criativos e devaneio, op. cit., p. 38.

(5) Ibidem, p. 42.

(6) Ibidem, p. 34-35. de um destino alheio à sua vontade e felicidade, de um destino que ele não controla e que é todo o tempo comentado e vigiado pela comunidade. É assim que, ao se perceber como um personagem preso nas teias narrativas de uma lógica abominável e dolorida, ele resolve, ilógico, recriá-la. Nesse momento, o narrador comenta: "Crivel? Sábio sempre foi Ulisses, que começou por se fazer de louco". Jó Joaquim, então, constrói sua própria estória (ou história) segundo sua "idéia inata de felicidade", desenredando as tramas alheias ao seu desejo. É para compreender este ponto que a contribuição da psicanálise se faz valiosa.

Freud define a fantasia como "sonho diurno", e afirma: "Podemos partir da tese de que a pessoa feliz nunca fantasia, somente a insatisfeita. As forças motivadoras das fantasias são os desejos insatisfeitos, e toda fantasia é a realização de um desejo, uma correção da realidade insatisfatória". ${ }^{4}$ Esses desejos são, ou de caráter ambicioso, destinados a realçar a personalidade, ou são desejos eróticos, de aspiração amorosa. Queremos mostrar que em "Desenredo" a estória criada por Jó Joaquim move-se exatamente seguindo estes dois desejos. O desejo erótico é claro, pois sua "estória" permite-lhe reaver a companhia da Mulher. O segundo desejo, de fundo narcísico, é menos evidente, mas podemos detectá-lo se pensarmos que, ao redimir a mulher, Jó Joaquim sai engrandecido, passando da situação de "pseudopersonagem" para a de "inédito poeta e homem", aproximando-se, inclusive, da figura heróica de Ulisses. Se, ao invés de dizer que a mulher nunca o traíra, ele tivesse dito: "ela traiu, mas eu a quero assim mesmo", o personagem poderia até obter o retorno da mulher, mas não alcançaria o aplauso e o consenso social, pois passaria por tolo, sendo figura ridicularizada e apequenada. Sua inteligência e sagacidade encontra-se no fato de conseguir ao mesmo tempo reaver a mulher e recuperar o orgulho ferido. Para Freud, mesmo as narrativas que versam sobre a fragmentação do sujeito têm sempre como herói ... "Sua Majestade o Ego, o herói de todo devaneio e de todas as histórias". ${ }^{5}$

Livrar-se à fantasia é, diz Freud, construir "castelos no ar" (ou feitos de ar). Encontramos em "Desenredo" uma imagem semelhante, pois quando J.J. opera a reviravolta no enredo, o narrador pergunta: "Incrível? É de notar que o ar vem do ar". Freud estabelece ainda um paralelo entre o criador literário e a criança que brinca e cria um mundo de fantasia levado a sério, anulando portanto a oposição jogo / realidade. Por isso, diz Freud, "é somente quando o adulto reencontra uma disposição psíquica próxima dos jogos de infância que ele pode se livrar da opressão que faz da vida um fardo, conquistando o alto ganho de prazer que é o humor". ${ }^{6}$

Pode-se dizer que há algo de processo infantil no refazimento da história operada por Jó Joaquim, pois ele nega uma realidade desconfortável (a traição da mulher) para adaptá-la a seus anseios e desejos mais profundos. Assim, numa visão normativa da psicanálise poder-se-ia incluir o personagem na categoria de um caso patogênico, lendo o conto como uma história de alienação e mentira. Sabemos no entanto que essa leitura minimiza o alcance do texto, pois se trata de um conto que questiona justamente os limites entre fato e ficção, entre verdade e fingimento.

Como vimos, "Desenredo" é uma história de amor a que não falta o final feliz: "Haja o absoluto amar - e qualquer causa se irrefuta", diz o narrador. Mas o que distingue esse final feliz do de outras fábulas, e confere a este conto o 
(m) Sigmund FREUD. "Quinta Lição", in -. Cinco Lições de Psicanálise; Contribuiçōes à Psicologia do Amor. Trad. do alemão por Durval Marcondes et al. São Paulo: Imago, 1997. p. 59.

(8) ROSA. "Aletria e hermenêutica", in Tutaméia, op. cit.

(9) Cf. ROSA in Günter LORENZ. "Diálogo com Guimarães Rosa" in Eduardo COUTINHO (Org.) Guimarães Rosa-Fortuna Crítica. Rio de Janeiro: Civilização Brasileira, 1983, p. 11: "Nós, o cientista e eu, devemos encarar a Deus e o infinito, pedirlhes contas, e, quando necessário, corrigi-Ios também, se quisermos estatuto de obra literária refinadíssima, é que aqui a felicidade é fruto de uma construção fictícia, de uma estória inventada e que, apesar de inventada, tornase mais real do que a realidade (ou então do que se tinha como realidade e que talvez não passasse de outra fabulação). Da mesma forma, a noção do que seja traição é posta em suspenso. Afinal, a mulher traiu ou não traiu, pergunta o leitor, atônito, ao final do conto. Queremos com isso dizer que o narrador que conta a seus ouvintes a história de Jó Joaquim pode estar, metalingüisticamente, contando a estória de constituição de outro narrador, numa narrativa que pōe à descoberto seu próprio fazer, ou melhor, desfazer. Neste caso, as verdades iniciais (Jó Joaquim como amante e marido traídos) já seriam fabulações, e a originalidade do conto encontra-se justamente no fato de o personagem refazer esses enredos, reivindicando o direito à autoria. Assim, aqui, como em outros textos de Guimarães Rosa, o ato de fabular é tido como uma ato de saúde e de libertação, pois é através dele que o personagem deixa de ser sujeito à criação para tornar-se sujeito criador. O conto estaria nos dizendo que a felicidade só é encontrada depois que o personagem se transforma em autor de seu destino.

Ao desfazer o enredo, Jó Joaquim "Criava nova, transformada realidade, mais alta. Mais certa?", pergunta o narrador que fala a seus ouvintes. Essa pergunta sustenta uma noção de "estória", contrária à história oficial, e que estaria mais próxima, ao que tudo indica, de um sentido metafísico e espiritual. É assim que, quando o personagem redime a mulher, o narrador comenta: "Ele queria apenas os arquétipos, platonizava. Ela era um aroma". Em Freud, o conceito de sublimação remete a uma forma de ascese, e é importante notar que ele não implica a erradicação dos desejos, mas a sua conscientização e conseqüente direcionamento para uma outra finalidade que, talvez, diz Freud, nem seja sexual: "Exatamente os componentes do instinto sexual se caracterizam por essa faculdade de sublimação, de permutar o fim sexual por outro mais distante e de maior valor social". ${ }^{7}$ O que se pode depreender desses textos de Freud aqui citados é que o poeta é aquele que torna conscientes os desejos (que a maioria tem vergonha de confessar), direcionando-os a um fim mais alto - o da criação estética.

Jó Joaquim seria assim uma espécie de representante ficcional do escritor, do artista e do poeta que, segundo Rosa, deve saber que: "Tudo está escrito; leia-se, pois, principal, e reescreva-se", ou: "Tudo se finge primeiro, germina autêntico é depois". ${ }^{8}$ Se o passado, como diz ò narrador do conto, é um "pálido rascunho", ele não só pode, como deve ser reescrito, pois, incompleto, não possui a verdade final. Encontramos aqui um eco da voz de Guimarães Rosa quando, em entrevista a Günter Lorenz, defendeu a idéia de que o escritor, para ajudar ao homem, deve se permitir, inclusive, corrigir a Deus. ${ }^{9}$

Essa noção desvenda, a nosso ver, a relação do personagem com o Jó bíblico, do Livro sapiencial, considerado "o texto bíblico mais ousado e inovador em sua visão de Deus, do homem e da criação"10 - e que em Guimarães Rosa ficará duplo: Jó Joaquim, misto de Bíblia com almanaque de anedotas, como discutiremos adiante. $\mathrm{O}$ Livro de Jó nos apresenta uma discussão sobre 0 porquê do sofrimento humano e da injustiça de um Deus todo-poderoso, que se converte em déspota ante o homem. Jó sofre com paciência, mas não passivamente, pois deseja obter uma explicação divina ante uma injustiça, que, nós sabemos, foi causada por Satanás para pôr à prova a fé humana. Como diz Moshe Greenberg, no comentário ao livro: "seu sofrimento imerecido abre-lhe 
ajudar o homem ... Sim! a língua dá ao escritor a possibilidade de servir ao homem e de vencer o diabo, inimigo de Deus e do homem".

(10) Cf. Robert ALTER, "Introdução ao Antigo Testamento", in Guia Literário da Bíblia. Robert Alter e Frank Kermode (Org.). Trad. Raul Filker. São Paulo: Editora UNESP, 1997, p. 27.

(i1) Moshe GREENBERG, "Jó", in Guia Literário da Biblia, op. cit., p. 310 e 324.

(12) ROSA, "Aletria e hermenêutica", in Tutaméia. op. cit.

(13) A. JOLLES. "O chiste", in Formas Simples. Trad. Álvaro Cabral. São Paulo: Cultrix, s. d, p. 205 16.

(14) Cf. Sigmund FREUD, Os chistes e sua relação com o Inconsciente. Trad. Jayme Salomão, os olhos à injustiça patente na sociedade em geral", e, "com suas ironias e surpresas, suas afirmações e argumentos em uma tensão que não é resolvida, $o$ Livro de Jó permanece a expressão clássica, na literatura mundial, do anseio irreprimível pela ordem divina, frustrada mas nunca sufocada pela desordem da realidade". " Nesse sentido, a estória (história) de Jó Joaquim é também uma questão de justiça, de anseio pela ordem divina sufocada pela desordem da realidade, implicando a ultrapassagem do sofrimento em direção ao reencontro da felicidade.

\section{O CHISTE}

"A estória", diz Rosa no prefácio "Aletria e hermenêutica" que abre Tutaméia, "não quer ser história. A estória, em rigor, deve ser contra a História. A estória, às vezes, quer-se um pouco parecida à anedota." Nesse mesmo sentido, a subversão do real através de uma narrativa que desfaz a verdade estabelecida, pondo-a em suspenso, indicaria a existência de um "supra-senso", próximo do nonsense. O próprio Rosa define: "Não é o chiste rasa coisa ordinária; tanto seja porque escancha os planos da lógica, propondo-nos realidade superior $\mathrm{e}$ dimensões para mágicos novos sistemas de pensamento". ${ }^{12}$

De fato, para finalizar, faremos menção ao fato de que "Desenredo" é um conto que se filia à "forma simples" do chiste (também chamado anedota, gracejo ou dito espirituoso), seja em relação ao tema como aos procedimentos formais. No capítulo dedicado ao assunto, André Jolles oferece-nos uma definição que se casa perfeitamente com o título do conto "Desenredo", pois ele afirma: "o chiste, onde quer que se encontre, é a forma que desata coisas, que desfaz nós".13 Continua Jolles sua argumentação, dizendo que o chiste desfaz os nós da linguagem, da lógica, da ética e até mesmo o das próprias formas simples, quando, por exemplo, transforma um provérbio e desfaz a experiência cristalizada na locução. Essa última característica da atividade chistosa - a inversão de provérbios ou de expressões idiomáticas - remete a um dos procedimentos marcantes do estilo de Guimarães Rosa presente em "Desenredo" nas frases: "num abrir e não fechar de ouvidos", "a bonança nada tem a ver com a tempestade", "vá-se a camisa que não o dela dentro" - entre outras, que enunciam sentenças, subvertendo sua ordem e significado primeiro. Ao desfazer os nós, o chiste, diz Jolles, cria um universo positivo que é o do cômico - "um universo em que todas as coisas se atam, ao desfazerem-se ou ao desatarem-se".

É possível que Jolles tenha lido o alentado estudo de Freud sobre o mesmo assunto, pois algumas de suas observações estabelecem um paralelo com as colocações freudianas, sobretudo quando ele diz que o chiste tem o propósito de "descarregar uma tensão", de forma a permitir "a libertação do espírito". Para Freud, o chiste atua justamente como um "alívio psíquico", possibilitando uma "economia na despesa psíquica" do indivíduo, e transformando-se assim em fonte de prazer para quem o elabora e para quem o escuta. ${ }^{14} \mathrm{Diz}$ ainda Freud que as diferentes técnicas de criação do chiste atuam "como procedimentos de restabelecimento de velhas liberdades e de liberação da carga de instrução inte- 
Rio de Janeiro: Imago, 1977.

(15) Ibidem, p. 150.

(16) FREUD, “Os propósitos dos chistes", in Os Chistes $e$ sua relação com o Inconsciente, op. cit., p. 130.

(17) Ibidem, p. 131.

(18) Ibidem, p. 136.

(19) Ibidem, p. 148.

(20) ROSA, "Sobre a escova e a dúvida", in Tutaméia, op. cit., p. 153. lectual". ${ }^{15}$ Outro ponto em comum entre Jolles e Freud encontra-se quando o primeiro afirma a relação do chiste com a inconveniência: "a inconveniência significa o desenlace das regras prescritas pela moral prática, pelos bons costumes e pelas conveniências sociais".

Dentre os vários tipos de chiste estudados por Freud, há um, que ele denomina de "cínico" (blasfemos ou críticos) e cujo propósito é atacar não só pessoas, como também as instituições e os dogmas morais ou religiosos. O que esse tipo de chiste revela é: "Nada é mais importante que o prazer e pouco importa como obtê-lo', o que" - diz Freud - "soa chocantemente imoral, e de fato o é - o que estes chistes sussuram pode ser dito em voz alta: que as vontades e desejos dos homens tem o direito de se tornarem aceitáveis ao lado de uma moralidade severa e cruel" ${ }^{16}$ Percebe-se então que o chiste nasce de um conflito ante a moralidade e os arranjos sociais coercitivos que impedem a plena realização do desejo. Como exemplo, Freud mostra que a instituição mais atacada por esse tipo de chistes é a do casamento, pois, "não existe reivindicação mais pessoal que a da liberdade sexual e em nenhum outro ponto a civilização exerceu supressão mais severa que na esfera da sexualidade" ${ }^{17}$

Citamos ainda uma outra classe de chistes, que Freud chama de "céticos", porque encontram ressonância especial no conto que analisamos e, de certo modo, confirmam nossa tese interpretativa: "a mais séria substância (desse tipo de) chiste é o problema do que determina a verdade ... O que eles atacam não é uma pessoa ou uma instituição, mas a própria certeza de nosso conhecimento, uma de nossas capacidades especulativas". ${ }^{18}$ A rebelião contra a compulsão da lógica e da realidade, diz Freud, "é profunda e duradoura". E completa: "Mesmo o fenômeno da atividade imaginativa pode ser incluído nessa categoria [rebelde]". ${ }^{19}$

Concluímos dizendo que a rebeldia de Jó Joaquim é o que o aproxima dos loucos e das crianças, mas é também a partir dessa rebeldia, levada a cabo a partir de um encontro amoroso com a Mulher, que ele se faz poeta. Segundo afirmação do próprio Guimarães Rosa, "São esdrúxulos freqüentemente os que resguardam a paz e a liberdade". ${ }^{20}$

ABSTRACT: This study redevelops an analysis of the short story "Desenredo" by Guimarães Rosa (Tutaméia, 1967) done some years ago. That reading was tied strictly to literary theory. Now we have elaborated, adding some reflections from psychoanalysis based specifically on two of Freud's studies: Humor and its relationship to the unconscious (1905) and Creative writers and reverie (1908).

KeYwords: Guimarães Rosa; Tutaméia; literature and psychoanalysis; humor; The Book of Job. 